\title{
MALIGNANT TUMORS IN PATIENTS WITH
}

\section{TYPE 2 DIABETES MELLITUS AND OBESITY}

\author{
S.V. Shymanets, L.I. Danilova, M.L. Lushchik, V.S. Dudarev, A.V. Karman, S.A. Kharuzhyk, V.S. Dovgalo
}

\author{
N.N. Alexandrov National Cancer Centre of Belarus \\ Belarusian Medical Academy of Post-Graduate Education
}

\section{OBJECTIVES}

The aim of the research was to identify cancer incidence distribution in Belarusian patients with type 2 diabetes mellitus.

\section{METHODS}

\begin{abstract}
A retrospective study of cancer incidence distribution was conducted in patients with diabetes mellitus according to the analysis of case records in 2013 at N.N. Alexandrov National Cancer Centre of Belarus.

The study group included 73 patients: $46(63 \%)$ women (mean age $65 \pm 8$ years) and 27 (37\%) men (70 \pm 7 years) with concurrent diabetes and cancer treated at Alexandrov National Cancer Centre of Belarus in 2013. The mean time of type 2 diabetes mellitus course before cancer diagnosis was 7,8 $\pm 5,8$ years. A meaningful associations between diabetes and cancer incidence in men and women subgroups were analyzed.
\end{abstract}

MALIGNANT TUMORS IN PATIENTS WITH TYPE 2 DIABETES MELLITUS AND OBESITY

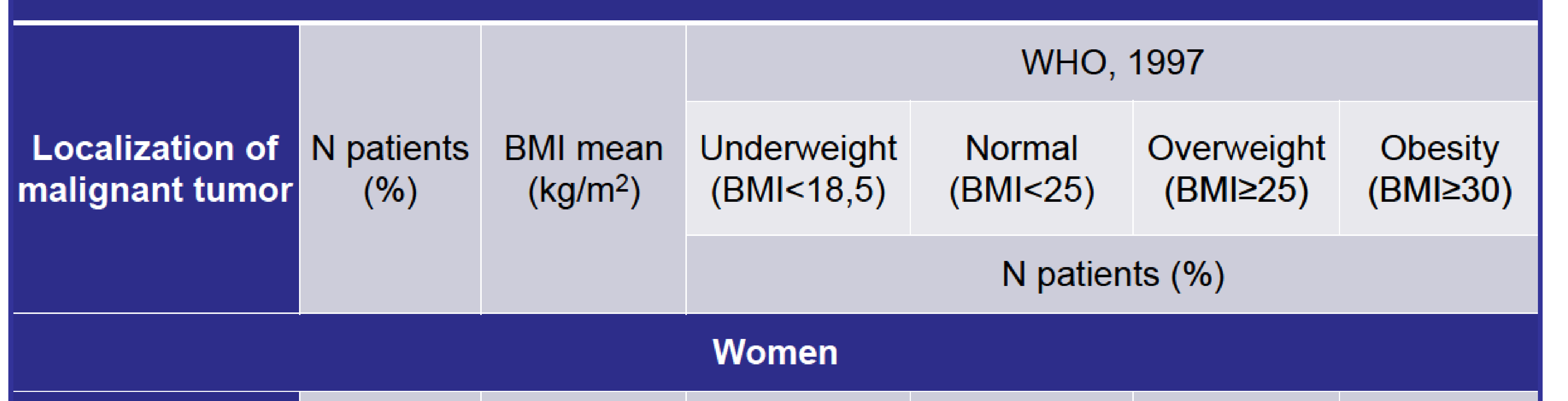

Breast

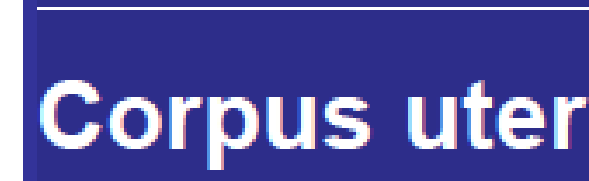

Cervix uteri

Lung

Another

localizations

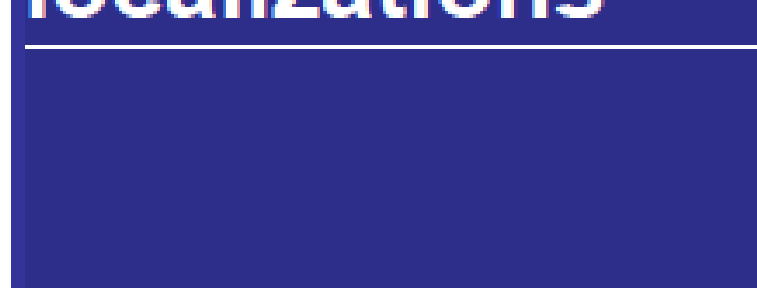

Lung

Prostate

Stomach

Urinary bladder

Kidney

Another

localizations

\begin{tabular}{|c|c|c|c|c|c|}
\hline $27(59 \%)$ & $32,9 \pm 7,1$ & $1(4 \%)$ & $2(7 \%)$ & $7(26 \%)$ & $17(63 \%)$ \\
\hline $7(15 \%)$ & $38,1 \pm 6,4$ & - & - & $1(14 \%)$ & $6(86 \%)$ \\
\hline $3(7 \%)$ & $36,2 \pm 8,6$ & - & - & - & $3(100 \%)$ \\
\hline $2(4 \%)$ & $30,5 \pm 2,1$ & - & - & $1(50 \%)$ & $1(50 \%)$ \\
\hline $7(15 \%)$ & $34,8 \pm 4,9$ & - & - & $1(14 \%)$ & $6(86 \%)$ \\
\hline $46(100 \%)$ & $34,1 \pm 6,7$ & $1(2 \%)$ & $2(4 \%)$ & $10(22 \%)$ & $33(72 \%)$ \\
\hline $6(22 \%)$ & $30,6 \pm 7,3$ & - & $1(17 \%)$ & $2(33 \%)$ & $3(50 \%)$ \\
\hline $5(19 \%)$ & $27,9 \pm 3,0$ & - & $1(20 \%)$ & $2(40 \%)$ & $2(40 \%)$ \\
\hline $4(15 \%)$ & $33,2 \pm 4,2$ & - & - & $1(25 \%)$ & $3(75 \%)$ \\
\hline $3(11 \%)$ & $33,8 \pm 7,7$ & - & - & $2(67 \%)$ & $1(33 \%)$ \\
\hline $2(7 \%)$ & $28,0 \pm 6,8$ & - & $1(50 \%)$ & - & $1(50 \%)$ \\
\hline $7(26 \%)$ & $29,8 \pm 4,6$ & - & $2(29 \%)$ & - & $5(71 \%)$ \\
\hline $27(100 \%)$ & $30,5 \pm 5,4$ & - & $5(19 \%)$ & $7(26 \%)$ & $15(55 \%)$ \\
\hline
\end{tabular}

CONCLUSIONS

Breast cancer predominated in women (59\%) with diabetes mellitus and lung cancer $(22 \%)$, prostate cancer $(19 \%)$ in men. Most of the patients had obesity and overweight. $18 \%$ of the patients had multiple primary malignancies. The mean time of type 2 diabetes mellitus course before cancer diagnosis was $7,8 \pm 5,8$ years. Future researches are needed for better understanding of possible biologic links between diabetes and cancer risk.

\section{RESULTS}

Among women breast cancer was the leading malignancy, accounting for 59\% (27 patients), corpus uteri cancer mentioned in $15 \%$ (7 patients), cervix in $7 \%$ (3 patients), lung in 4\% ( 2 patients), other localizations occurred in $-15 \%$ ( 7 patients). In men subgroup the higher incidence were registered for lung and prostate cancers, accounting for $22 \%$ ( 6 cases) and $19 \%$ (5 cases) accordantly, stomach cancer revealed in $15 \%$ (4 persons), bladder $-11 \%$ (3 persons), kidneys $-7 \%$ ( 2 persons), other localizations $-26 \%$ (7 persons). Multiple primary malignancies were diagnosed in $18 \%$ (10 women and 3 men). The most frequent initial cancer types were women breast ( 5 patient), lung ( 2 patients), and corpus uteri ( 2 patients), the other types made stomach, colon, cervix uteri cancer and myeloleucosis. 